\title{
The true value of the touch
}

The skin was understood as a tissue of protection and containment and an efficient thermal insulation of the body. By exploring the action of the touch, physiologists have described different sensors and their physiological connections, giving us a definite framework of how we perceive the world. ${ }^{1}$

Besides, when we touch another person, we can transmit intentions, such as the affective ones. The skin is also a mean of communication without words. The touch perception is present in the fetus, and the baby recognizes soft and slow strokes, as well as the abrupt ones. This stimulus that accompanies us through life is responsible for the creation of ties, stimulation of the healthy affective, social and cognitive development and capacity of body self-recognition ${ }^{2}$.

The connection between the skin stimulation and the performance of neuroendocrine and immune systems is a consensus and it has biopsychobehavioral consequences essential to the quality of life and the chances of survival. ${ }^{3}$

One of our recent findings shows that the behavioral responses triggered by the touch are related to fibers named C-tactile (CT) afferents, which are demyelinating, transmit information in a speed 50 times lower than the mechanoreceptors and exist in skin regions with fur or fuzz. Patients with neuropathies losing myelinated fibers can report to the body region that is being touched, and the stimulus is recorded in the insular region of the brain, connected to the limbic system, which is responsible for emotions and body recognition. In typical cases, recent theories point to the interaction at first between mechanoreceptors and TC fibers and, also, to an interaction between all forms of sensory inputs:

\section{REFERENCES}

1. Grunwald M, editor. Human haptic perception.Basel: Birkhäusen; 2008. visual, smell, taste, hearing, kinesthetic and haptic perception ${ }^{3}$.

The skin is structured primarily on the connective tissue and on the musculoskeletal system. It affects and is affected by them. Thus, the muscle tension that we impose constantly and the way we take care of our bodies affect the way the skin perceives the world and ourselves. It affects reflexively the internal skin-muscle-organs function ${ }^{2}$.

The delicate balance of the skin functions is also sustained by the emotional balance and vice versa. It is believed that emotions related to personality characteristics and coping skills can determine the physical posture to establish a body model that reflects the way one thinks and acts, and hence the state of skin tension. To mobilize this skin frame can trigger physical reactions of protection against changes and, in some cases, emotional and behavioral reactions of unconscious origin ${ }^{2}$.

From the more traditional massages to the body therapies, skin manipulation remains a constant and must gain a new look of the physical therapist. In the end, what is expected is a malleable, comfortable and confident body, a mind that is clear and without suffering and a posture that expresses all of this. A body in which the sensations, perceptions, functions, movements and feelings interact in harmony.

Prof. Fátima A. Caromano
Department of Physical Therapy, Speech Therapy
and Occupational Therapy
School of Medicine
University of São Paulo

2. Cruz CMV, Caromano FA. Como e por que massagear o bebê: do carinho às técnicas e fundamentos. Barueri: Ed. Manole; 2011.

3. Stein BE, editor. The new handbook of multisensory processing. EUA: MIT Press; 2012. 